\title{
Percentage of faecal excretion of meloxicam in the Cape vultures (Gyps corprotheres)
}

Emmanuel Oluwasegun Adawaren ${ }^{1}$, Lilian Mukandiwa ${ }^{1,2}$, John Chipangura ${ }^{2}$ Kerri Wolter and Vinny Naidoo ${ }^{1,2^{*}}$

${ }^{1-}$ Department of Paraclinical Science, Faculty of Veterinary Science, University of Pretoria, South Africa.

${ }^{2-}$ Biomedical research Centre, Faculty of Veterinary Science, University of Pretoria, South Africa.

*Corresponding author: Emmanuel Oluwasegun Adawaren adawarenvet1@yahoo.com +27747749213. Department of Paraclinical Science, Faculty of Veterinary Science, University of Pretoria, Soutpan Road 0110, Pretoria, South Africa

\section{Highlights}

- Develop and validate a high performance liquid chromatography (HPLC) for the quantification of meloxicam in vulture faeces.

- Evaluate pharmacokinetic parameter of meloxicam in Cape vulture $10 \mathrm{~h}$ post administration using HPLC.

- Evaluate faecal concentration of non-metabolised meloxicam $24 \mathrm{~h}$ post administration using HPLC method.

- Investigate the reason (s) for meloxicam safety in old world vultures. 


\section{Introduction}

In 2004 Oaks et al, established that three species of Asian Gyps vultures (Gyps indicus, Gyps tenuirostris and Gyps bengalensis) were extremely susceptible to the effects of diclofenac [(2-[2(2,6-dichloroanilino) phenyl-acetic acid)] to such an extent that the drug killed nearly $99 \%$ of the population (Oaks et al. 2004, Green et al. 2004, Swan et al. 2006b). In order to prevent the extinction of these endangered species of birds, diclofenac was banned in 2006 by the government of the affected countries and the safe alternate meloxicam [4-hydroxy-2-methyl-N-(5-methyl-2thiazolyl)-2H-1,2-benzothiazine-3-carboxamide-1,1-dioxide], also a non-steroidal antiinflammatory drug (NSAID), was advocated (Swan et al. 2006a). The advocacy of meloxicam as a safe alternative was based on an extensive safety study, where the absence of apparent ill effect of the drug administered to 35 White-backed (Gyps africanus) vultures, another species susceptible to diclofenac, was demonstrated in birds under both captive and wild conditions. For these studies the estimated likely maximum levels of exposure (MLE) $(1.83 \mathrm{mg} / \mathrm{kg})$ was converted to a drug dose of $2 \mathrm{mg} / \mathrm{kg}$, and administered by oral gavage with no clinical sign of renal toxicity or elevated plasma uric acid. The safety of meloxicam as residues was also subsequently demonstrated by feeding birds meat harvested from cattle slaughtered a short period after being treated with meloxicam at 1 $\mathrm{mg} / \mathrm{kg}$ for five days (twice the recommended dose). The safety of meloxicam has since been demonstrated in the G. bengalensis, G. indicus and G. coprotheres (Swan et al. 2006a). As a result of the advocacy on the use of meloxicam and the concurrent ban on the sale of diclofenac for veterinary use, the previous rate of decline has been slowed with the population finally showing a small degree of recovery (Cuthbert et al. 2011, Cuthbert et al. 2016). For example in Pakistan, there was an increase vulture nesting sites from 11 observed during a survey conducted between 20102011 to 34 between 2011-2014 (Murn et al. 2015).

While the use of meloxicam was a major contributor in mitigating the rate of declines in vulture numbers, the reason for meloxicam's safety and diclofenac's toxicity remains unknown, especially 
with both drugs meant to work through the same physiological mechanism. In one explanation, it was suggested that the drug's pharmacokinetics and related species specific metabolism was the important determinant in toxicity, with zero order metabolism being a feature in toxicity (Naidoo et al., 2010). From in vivo studies in the Cape griffon vulture (Gyps coprotheres), meloxicam had a short elimination half-life of 0.50 hour in comparison to diclofenac with a half-life of 12.24 hours (Naidoo et al. 2008, Naidoo et al. 2009). The role of the half-life in toxicity was also very evident in studies with ketoprofen [2-(3-Benzoylphenyl) propanoic acid] and carprofen [2-(6-Chloro-9Hcarbazol-2-yl) propanoic acid] in which deaths were only recorded in Gyps vultures with longer half-life of elimination of 7.37 and 37.75 hours for ketoprofen and carprofen respectively. While those who survived had elimination half-lives of 3.24 and 13.99 hours for ketoprofen and carprofen (Naidoo, Wolter \& Botha 2017, Naidoo et al. 2010).

The metabolism of the NSAIDs is also markedly different to that reported in man and other mammalian species in that meloxicam is the slowest metabolised in these other species whilst being rapidly metabolised in the vulture (Naidoo et al. 2008, Engelhardt 1996, Hasan et al. 2005, Ishizaki et al. 1980). The difference in the metabolism of the different NSAIDs presents an unexpected finding, since the NSAIDs should be metabolised by the same or similar CYP450 enzymes. This tends to suggest that either different CYP enzymes are responsible for the metabolism of the different NSAIDs like meloxicam and diclofenac in birds versus mammals, or possibly that meloxicam is excreted unchanged i.e. rapid plasma clearance can be indicative of metabolism or rapid excretion of the primary drug. This concept is not too different from evidence available thus far, as meloxicam is general well excreted as one of two major metabolites (i.e. 5'-hydroxymethyl metabolite and 5'-carboxyl metabolite) in the rat, mice, mini-pig, baboon and dog (Busch et al. 1998) in support of metabolic similarity, while in the cat where the drug undergoes hepatic excretion as $50 \%$ unchanged drug supports rapid elimination as unmetabolised drug (Grudé et al. 2010). For this study we attempt to obtain a better understand for the rapid plasma clearance of 
meloxicam in the vulture, using the Cape griffon vulture (Gyps coprotheres), as the test species. To achieve this, we studied the total concentration of drug in the plasma over a ten hour period as well as the total amount of unchanged meloxicam in the faeces over a 24 hour period.

\section{Materials and Methods}

\subsection{Materials}

Meloxicam (Petcam, Ceva Animal Health, South Africa), HPLC grade acetonitrile (Merck, Darmstadt, GE), $5 \mathrm{ml}$ syringe and needle, $2 \mathrm{ml}$ Eppendorf tube, $5 \mathrm{ml}$ screw capped glass tube, nitrogen gas was obtained from Afrox (Johannesburg, South Africa). Equipment comprised of a vacuum water bath, Beckman Allegra TM FX-22R centrifuge (Beckman Coulter, Palo Alto, CA, USA), and a Beckman System Gold high performance liquid chromatograph (HPLC), equipped with a 126 Solvent Module, a 168 PDA detector, a 508 autosampler, and 32 Karat 8.0 software (Beckman Coulter, Fullerton, CA, USA). Chromatographic separation was achieved with a Thermo Scientific BDS HYPERSIL C18 HPLC column (Thermo Scientific, Runcorn, UK), dimensions: $250 \mathrm{~mm}$ X $4.6 \mathrm{~mm}$ X $5 \mu \mathrm{m}$.

\subsection{Animals and Experimental Protocol}

The study was approved by the Animal Ethics Committee (AEC) of the University of Pretoria, South Africa, with project number V014-17. Cape Griffon vultures (n=6), all nonreleasable, were sourced from VulPro conservative centre. All birds used in this study were in captivity for at least one year prior to inclusion in the study. For the study the birds were transferred and housed within the University of Pretoria Biomedical Research Centre (UPBRC) aviaries in individual metal cages ( $1.87 \mathrm{~m}$ high X $88 \mathrm{~cm}$ wide $\mathrm{X} 82 \mathrm{~cm}$ depth). The cages were spaced to allow for proper ventilation and each bird marked to allow for unique identification and observation. Each cage was provided with a urine pan for easy collection of excreta. The birds were at all times in 
visual contact with the rest of the birds recruited into the study. The vultures were fed twice weekly with $1 \mathrm{~kg}$ of beef each, bought from a commercial butchery and water ad libitum. The birds were returned to VulPro at the end of the study.

The birds were treated with a single dose of meloxicam by intramuscular injection into the breast muscle at a dose of $2 \mathrm{mg} / \mathrm{kg}$ body weight (Swan et al. 2006a). Blood samples (5ml) were collected from the tarsal or wing vein before drug administration and $0.5,1,1.5,2,6,8$, and 10 hours after treatment into a sterile $5 \mathrm{ml}$ syringe and immediately transferred into heparinised evacuated blood tubes. Samples were centrifuged within 2 hour of collection at $3000 \mathrm{~g}$ for $15 \mathrm{~min}$ at $4{ }^{\circ} \mathrm{C}$, and the supernatants stored at $-80{ }^{\circ} \mathrm{C}$ in polycarbonated tubes until analysed. The faecal samples produced were collected before dosing and after every two hours post dosing for the first ten hours and then again at 24 hours after dosing. The collected faecal samples were store at $-80{ }^{0} \mathrm{C}$ until analysed.

\subsection{Sample Analysis}

\subsubsection{Vulture plasma}

Plasma samples were analysed by a Beckman System Gold high performance liquid chromatograph (HPLC), equipped with a 126 Solvent Module, a 168 PDA detector, a 508 autosampler, and 32 Karat 8.0 software (Beckman Coulter, Fullerton, CA, USA). Chromatographic separation was achieved with a Thermo Scientific BDS HYPERSIL C18 HPLC column (Thermo Scientific, Runcorn, UK), dimensions: $250 \mathrm{~mm}$ X 4.6mm X 5 $\mu \mathrm{m}$. Aliquot of $250 \mu 1$ of plasma were pipetted into $2 \mathrm{ml}$ Eppendorf tube. $75 \mu \mathrm{l}$ of $1 \mathrm{M} \mathrm{HCL}$ and 1,250 $\mu \mathrm{l}$ of diethylether were added to the Eppendorf tube. The Eppendorf tube was vortexed for 2 min for protein precipitation and centrifuge at $9000 \mathrm{rpm}$ for $5 \mathrm{~min}$. The organic layer was transferred into another clean screw

capped glass tube and evaporated under nitrogen at $60{ }^{0} \mathrm{C}$. After drying, the residue was reconstituted in $200 \mu \mathrm{l}$ of the mobile phase and briefly vortex. About $30 \mu \mathrm{l}$ of the reconstituted 
sample was injected onto the column using an autosampler (Emara et al. 2016). The samples were analysed using an isocratic method with mobile phase of water-acetic acid (A) (99:1 v/v) and acetonitrile (B) at a ratio of 50 (A) : 50 (B), at a flow rate of $1000 \mu 1 / m i n$ with a total runtime of 12 min and a detection wavelength of $360 \mathrm{~nm}$ (Emara et al. 2016). Validation of the method was carried out by a calibration standard curve of meloxicam spiked vulture plasma ranging from 3.125$100 \mu \mathrm{g} / \mathrm{ml}$ in triplicate. 


\subsubsection{Faecal Analysis}

For the method validation 25mg of faeces (the solid and white urine components homogenised) were transferred into $5 \mathrm{ml}$ tube and spiked with $100 \mu \mathrm{l}$ of meloxicam standard concentration ranging from $3.125-100 \mu \mathrm{g} / \mathrm{ml}$ in triplicate. The spiked excreta sample was homogenised using $1000 \mu \mathrm{l}$ of acetonitrile using a manual homogenizer. The homogenate was transferred into $2 \mathrm{ml}$ Eppendorf tube and centrifuged at $10,000 \mathrm{rpm}$ for $10 \mathrm{~min}$ at $4{ }^{0} \mathrm{C}$. After centrifugation, the supernatant was transferred into a clean glass tube and evaporated to dryness at $60{ }^{0} \mathrm{C}$ under nitrogen. $30 \mu \mathrm{l}$ of the sample was injected onto the HPLC column, using the same method and equipment as above, with the exception that the mobile phase consisted of a ratio of 40 (A):60 (B) to achieve a clearer separation of the peak of interest. For samples analysis, , $25 \mathrm{mg}$ of the excreta were homogenized using $1000 \mu \mathrm{l}$ of acetonitrile and centrifuged at $10,000 \mathrm{rpm}$ for $10 \mathrm{~min}$ at $4{ }^{0} \mathrm{C}$. The supernatant of the treated samples were also dried under nitrogen at $60{ }^{\circ} \mathrm{C}$ and the dried residue reconstituted with $200 \mu \mathrm{l}$ of mobile at the mixture ratio as described above for meloxicam standard. Also, $30 \mu 1$ of the reconstituted sample was injected onto the HPLC column. To ensure the correct identification of the meloxicam peak from the metabolites, a process of standard addition was undertaken for a few samples at a concentration of 25,50 and $100 \mu \mathrm{g} / \mathrm{ml}$.. The meloxicam peak was confirmed on chromatogram by the increasing absorbance relative to concentration (results not shown). Only after the latter confirmation, were the actual sample analysed for their meloxicam concentration. On chromatogram, the metabolites were identified based on their retention time of 4.72 and 2.68 for 5'-hydroxylmethyl and the unknown hydroxyl-metabolite, based on the previous chromatograms published of 3.8 and 2.9 minutes for 5'-hydroxylmethyl and 5' unknown hydroxylmetabolite respectively (Naidoo et al. 2008). 


\subsection{Pharmacokinetic analysis}

All pharmacokinetic parameters were calculated with Kinetica 5.0 (Thermo) using a noncompartmental model. The maximum plasma concentration $\left(\mathrm{C}_{\max }\right)$ and the time to maximum concentration $\left(\mathrm{T}_{\max }\right)$ were read directly from the concentration versus time plasma profile. The area under curve to the last time point $\left(\mathrm{AUC}_{\text {last }}\right)$ and the area under the moment curve were determined using the linear trapezoidal rule. The total area under curve extrapolated to infinity $\left(\mathrm{AUC}_{\text {tot }}\right)$ was calculated as $\mathrm{AUC}_{\text {tot }}=\mathrm{AUC}_{\text {last }}+\mathrm{C}_{\text {Last }} / \lambda$ with $\lambda$ being the elimination rate constant. The half-life $\left(t_{1 / 2}\right)$, clearance $(\mathrm{Cl} / \mathrm{F})$; volume of distribution during terminal phase $\left(\mathrm{V}_{\mathrm{z}} / \mathrm{F}\right)$; volume of distribution at steady state $\left(\mathrm{V}_{\mathrm{ss}} / \mathrm{F}\right)$ and the mean residence time $(\mathrm{MRT})$ were determined as $\mathrm{t}_{1 / 2}=\ln (2) / \lambda ; \mathrm{V}_{\mathrm{z}}=$ $\mathrm{Cl} / \lambda=\operatorname{Dose} /\left(\mathrm{AUC}_{\mathrm{tot}} * \lambda\right) ; \mathrm{V}_{\mathrm{ss}}=\left(\right.$ Dose $\left.^{*} \mathrm{MRT}\right) / \mathrm{AUC}, \quad \mathrm{Cl}=\operatorname{dose} / \mathrm{AUC}_{\mathrm{tot}}$ and $\mathrm{MRT}=$ $\mathrm{AUMC}_{\text {tot }} / \mathrm{AUC}_{\text {tot. }}$ Pharmacokinetic parameters were described by standard descriptive statistics. The percentage of meloxicam excreted 24 hour post dosing was calculated as $\% \mathrm{E}=$ Sum of total meloxicam (mg) in faeces divided by plasma $\mathrm{AUC}_{\text {last }}$ multiple by 100 . The faecal half-life of meloxicam was calculated as Ln2 divided by slope of linear cumulative curve after 24 hour post meloxicam administration.

\section{Results}

\subsection{HPLC Validation}

For the spiked faecal samples the method was linear from 3.125-100 $\mu \mathrm{g} / \mathrm{ml}$, with the coefficient of determination $\left(\mathrm{r}^{2}\right)$ above 0.99 for three independent curves. The lower limit of detection (LLOD) of $0.195 \mu \mathrm{g} / \mathrm{ml}$ and the lower limit of quantification (LLOQ) was $0.391 \mu \mathrm{g} / \mathrm{ml}$. For the plasma samples, the method was linear from 3.125-100 $\mu \mathrm{g} / \mathrm{ml}$, with a co-efficient of determination above 0.99 for three independent runs. The lower limit of detection (LLOD) of $0.049 \mu \mathrm{g} / \mathrm{ml}$ and the lower limit of quantification (LLOQ) was $0.098 \mu \mathrm{g} / \mathrm{ml}$. The co-efficient of variation, percentage 
recovery of meloxicam for the two matrices are presented in Table 1. Both the 5'-hydroxylmethyl and the unidentified hydroxyl-metabolites were evident in the faeces. 
Table 1

Accuracy and precision of meloxicam in the faeces and plasma samples

\begin{tabular}{|c|c|c|c|c|c|c|c|c|}
\hline $\begin{array}{l}\text { Validation } \\
\text { Time }\end{array}$ & $\begin{array}{l}\text { Faecal Spiked } \\
\text { sample } \\
(\mu \mathrm{g} / \mathrm{ml})\end{array}$ & $\begin{array}{l}\text { Calculated } \\
\text { concentration } \\
(\mu \mathrm{g} / \mathrm{ml})\end{array}$ & $\mathrm{CV} \%$ & Recovery \% & $\begin{array}{l}\text { Plasma } \quad \text { Spiked } \\
\text { Sample }(\mu \mathrm{g} / \mathrm{ml})\end{array}$ & $\begin{array}{l}\text { Calculated } \\
\text { concentration } \\
(\mu \mathrm{g} / \mathrm{ml})\end{array}$ & $\mathrm{CV} \%$ & Recovery \% \\
\hline Intra-day & $\begin{array}{l}3.125 \\
12.5 \\
25 \\
50 \\
100\end{array}$ & $\begin{array}{l}3.19 \\
12.38 \\
22.57 \\
47.84 \\
101.70\end{array}$ & $\begin{array}{l}4.82 \\
2.37 \\
12.13 \\
3.00 \\
1.05\end{array}$ & $\begin{array}{l}102.10 \\
99.02 \\
90.26 \\
95.67 \\
101.70\end{array}$ & $\begin{array}{l}3.125 \\
6.25 \\
12.5 \\
25 \\
50 \\
100\end{array}$ & $\begin{array}{l}3.09 \\
6.55 \\
12.69 \\
27.18 \\
49.26 \\
101.46\end{array}$ & $\begin{array}{l}12.65 \\
9.99 \\
0.59 \\
3.48 \\
2.47 \\
1.45\end{array}$ & $\begin{array}{l}98.86 \\
104.83 \\
101.51 \\
108.72 \\
98.58 \\
101.46\end{array}$ \\
\hline
\end{tabular}



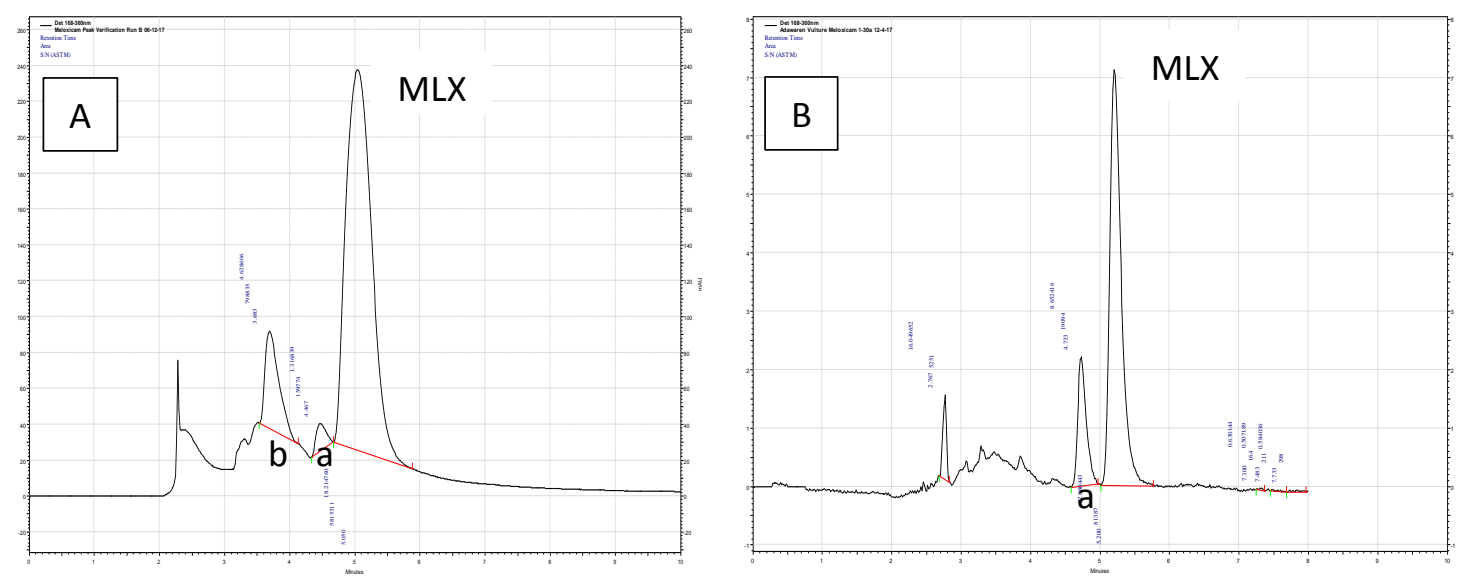

Fig.1 Chromatogram of meloxicam (MLX) 5'-hydroxylmethyl metabolite (a) and unidentified hydroxy-metabolite (b) from the faecal (A) and plasma sample (B).

\subsection{Plasma and hepato-renal pharmacokinetics of meloxicam}

The plasma pharmacokinetic parameters obtained by non-compartmental analysis are presented in Table 2, and the plasma concentration versus time profile is shown in Fig 2. All results are presented as geometric mean. The total plasma concentration $\left(\mathrm{C}_{\max }\right)$ of $92.79 \pm 7.96 \mu \mathrm{g} / \mathrm{ml}$ of meloxicam administered at $2 \mathrm{mg} / \mathrm{kg}$ body weight was achieved at $0.56 \pm 0.08 \mathrm{~h}\left(\mathrm{~T}_{\max }\right)$. The elimination half-life was $0.37 \pm 0.10 \mathrm{~h}$ with a mean residence time of $0.90 \pm 0.12 \mathrm{~h}$. The total plasma clearance was $0.02 \pm 0.00 \mathrm{l} / \mathrm{h} \mathrm{kg}$ and the steady state volume of distribution of $0.02 \pm 0.00 \mathrm{l} / \mathrm{kg}$. The hepato-renal pharmacokinetic parameters are presented in Table 3 and the hepato-renal concentration versus time curve is shown in Fig 3. Since birds don't have a urinary bladder the urinary excretory half-life could not be calculated. As a surrogate the hepato-renal excretory halflife was estimated at $3.78 \pm 3.02 \mathrm{~h}$ with $1.35 \pm 0.71 \%$ excretion of the parent drug being present in the total pooled excreted faeces over the 24 hours study period. In all cases, it appeared that excretion was complete after 24 hours, with no further increase in hepato-renal meloxicam concentration being evident at the 24 hour collection point. 
Table 2

Pharmacokinetic Parameters obtained by non-compartmental modelling following intramuscular injection of six Gyps coprotheres with meloxicam

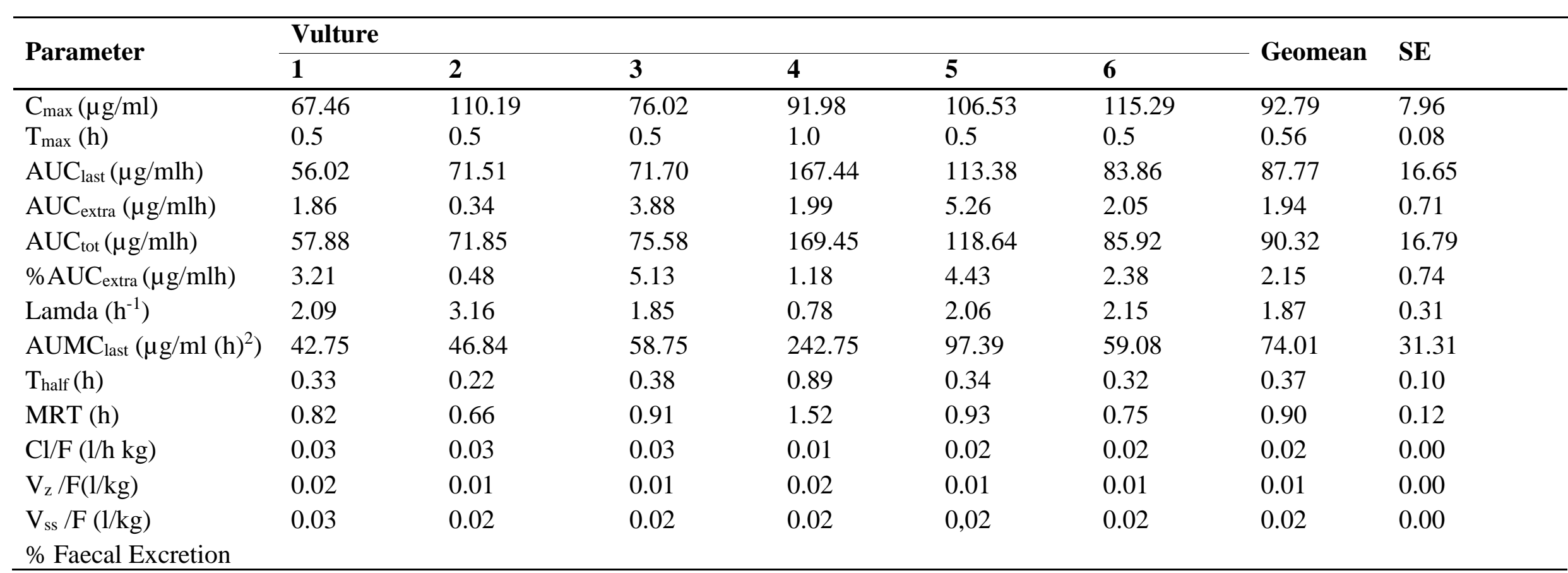

$\%$ Faecal Excretion

$\mathrm{C}_{\max }=$ maximum plasma concentration, $\mathrm{T}_{\max }=$ time to maximum concentration, $\mathrm{AUC}_{\text {last }}=$ area under curve to the last quantifiable time point, $\mathrm{AUCM} \mathrm{M}_{\text {last }}=\mathrm{T}_{\mathrm{T}}$ area under the moment curve from the time point zero to the last measured time point, $\mathrm{T}_{1 / 2}=$ half-life of elimination, $\mathrm{MRT}=$ mean residence time, $\mathrm{Cl} / \mathrm{F}=$ apparent $\mathrm{clearance}, \mathrm{V} / \mathrm{F}=$ apparent volume of distribution during terminal phase, $\mathrm{V}_{\mathrm{ss}} / \mathrm{F}=$ apparent volume of distribution at steady state, Lamda =elimination rate constant. 


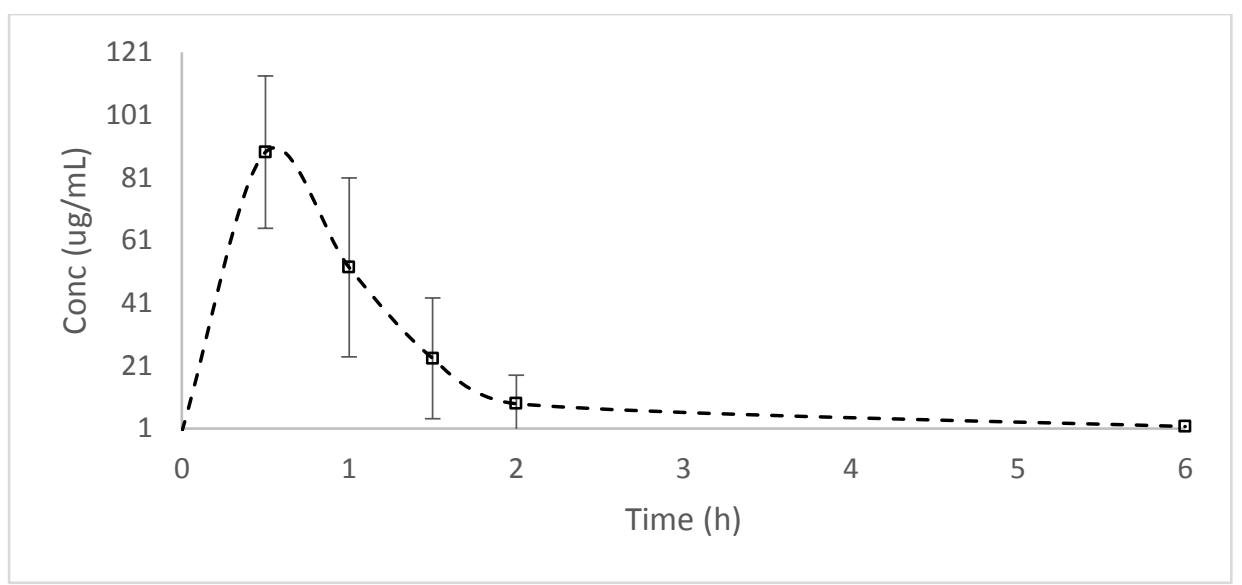

Fig. 2. Mean plasma concentration vs time curve following intramuscular meloxicam administration in adult Gyps coprotheres vultures

Table 3

Hepato-renal half-life and percent excretion following intramuscular administration of meloxicam in Gyps coprotheres vultures.

\begin{tabular}{lcccccccc}
\hline Parameter & V1 & V2 & V3 & V4 & V5 & V6 & Geomean SD & SD \\
\hline Slope & 0.31 & 0.27 & 0.39 & 0.09 & 0.17 & 0.08 & 0.18 & 0.12 \\
Cloacal T $_{1 / 2}(\mathrm{~h})$ & 2.25 & 2.57 & 1.80 & 7.72 & 4.10 & 8.84 & 3.78 & 3.02 \\
MLX \% excreted & 1.22 & 1.82 & 2.70 & 0.61 & 1.47 & 1.13 & 1.35 & 0.71 \\
\hline
\end{tabular}

Key note: V1-V6 indicate the individual vulture used in the study, MLX\%= meloxicam percent 


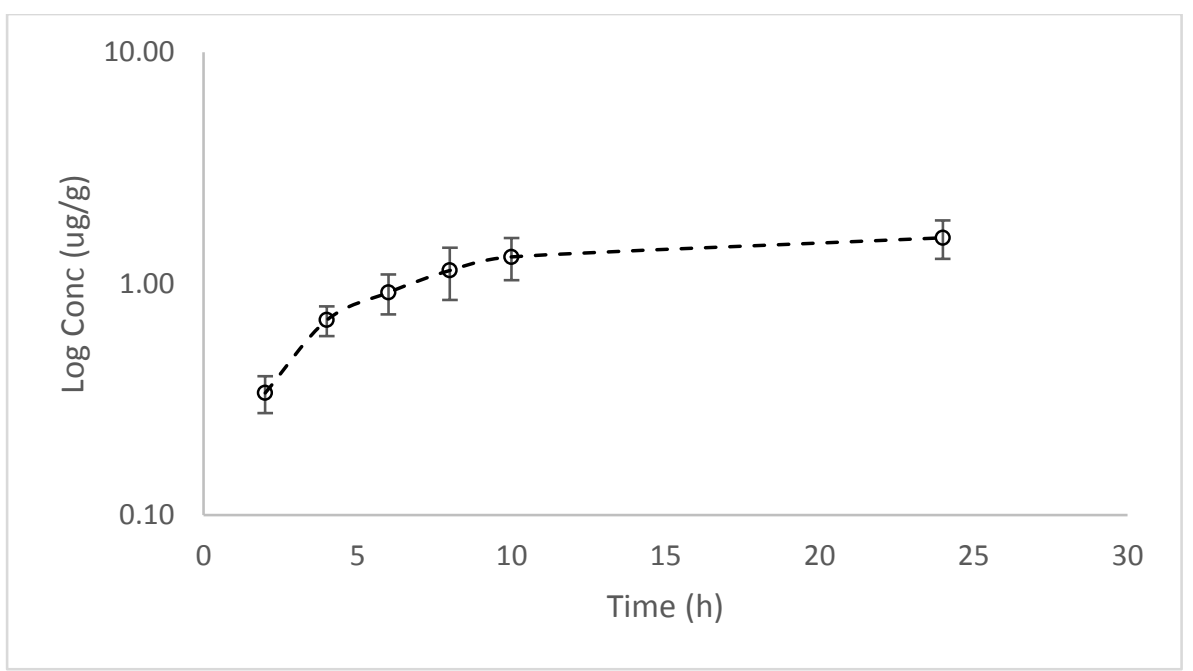

Fig. 3. Mean cumulative hepato-renal concentration vs time curve on the log scale following intramuscular meloxicam administration in adult Gyps coprotheres vultures (Error bars are presented as SEM)

\section{Discussions}

In the recent past, the extreme environmental toxic effect of diclofenac in vultures was mitigated in part by the introduction of meloxicam for use in cattle on the Indian subcontinent (Swan et al. 2006a). Despite the drugs being NSAIDs, the two drugs in vultures are not only distinguished by their marked differences in their safety profiles, but also their half-life of elimination (12.24 \pm 0.99 and $0.5 \pm 0.00$ hours for diclofenac and meloxicam respectively) (Naidoo et al. 2008, Naidoo et al. 2010, Naidoo et al. 2017). Surprisingly this is completely opposite to what happens in mammalian species whereby meloxicam tends to have a longer elimination half-life than other NSAIDs. For example, the following elimination half-life of meloxicam have been observed in mice $(6.41 \mathrm{~h})$, rat $(13.4 \mathrm{~h}), \operatorname{dog}(24 \mathrm{~h})$, pig $(121 \mathrm{~h})$, baboon $(6.12 \mathrm{~h})$ and human $(13.7 \mathrm{~h})$ (Hasan et al. 2005, Ishizaki et al. 1980, Busch et al. 1998). While diclofenac has the following half-life in human (1.5 h), dog (1.3 h), mice (2 h), rat (8.2 h), pig (2.4 h) and baboon (3 h) (Small 1989, Dutta et al. 2008, Torres-Lopez et al. 1997, Tsuchiya et al. 1980, Oberle et al. 1994, Faigle et al. 1988). 
For meloxicam to have a rapid elimination in complete contrast to the other NSAIDs for the same species, we speculate this may be as a result of the elimination of the non-metabolised drug into the gastro-intestinal tract. For this study, we establish the reason behind the rapid half-life of elimination of meloxicam in the vultures, using the Cape vulture as our indicator species, by evaluating the percentage of parent meloxicam excreted unchanged in the faeces of the vultures, since birds don't readily produce a separate urine and faecal fraction.

Following the intramuscular administration of meloxicam to six adult Cape vultures, meloxicam took on average 0.56 hour to reach the maximum plasma concentration of $92.79 \mu \mathrm{g} / \mathrm{ml}$. The profiles achieved from all the birds were in general very similar with the exception of one bird with a Tmax of one hour. The elimination half-life was 0.37 hours with a co-efficient of variation of $27 \%$, as a result of the same bird having a half-life elimination that was double for the other birds. The results from this study were similar to findings of a previous pharmacokinetic study in the same species (Naidoo et al. 2008). This implies that the pharmacokinetics of meloxicam is fairly constant amongst Cape griffon vultures. However, the difference observed in one of the vulture does indicate that a degree of intra-subject variation does exist in the species, which is not unexpected as the expression and function of the CYP450 enzymes are known to differ amongst individuals with resultant variability in drug response at the individual level. These factors are genetic (e.g. single nucleotide polymorphism, copy number variants, insertions, deletions and inversions), epigenetic (e.g. xenobiotic induction, regulatory effect of cytokines and hormones, age, sex), environmental and pathophysiological (Polimanti et al. 2012). The genetic variation of the CYP450 genes has resulted in people being characterised into extensive, intermediate, poor and ultrarapid metabolizers (Zangerand Schwab 2013). 
From the hepato-renal analysis, meloxicam was detected in small concentrations in the faeces of every bird sampled. The cumulative excretion of meloxicam showed that meloxicam was $1.35 \pm 0.71 \%$ after 24 hours with a co-efficient of variation of $117 \%$, for one of the vulture with the slowest half-life of 0.89 hours having a cumulative excretion twice lower than the other vultures, once again indicating that intra-individual variation in metabolism being present in the species. This result was not too dissimilar to other mammalian species reported to excrete non-metabolised meloxicam via renal and biliary routes for mice (0.2\%), mini-pig (1\%) and baboon (4\%) over a 24 hour period (Busch et al. 1998). This low cumulative excretion of parent meloxicam would thus indicate that in addition to been rapidly cleared from the plasma, meloxicam is rapidly and fairly completely metabolised in the vulture. The latter would thus rule out the excretion of nonmetabolised meloxicam as the reason for the rapid elimination of the drug in the Cape griffon vultures, and will explain why birds were protected from the exposure dose of $2 \mathrm{mg} / \mathrm{kg}$ in initial toxicity studies.

The short elimination half-life of meloxicam will also explain the environmental safety of the drug, as the drug is unlikely to have a cumulative effect. We based on a combination of pharmacokinetic features of meloxicam and behavioural habits of the birds. From a pharmacokinetic point using the longest half-life of 53 minutes, a bird would need to be exposed to a dose of $2 \mathrm{mg} / \mathrm{kg}$ every hour for a cumulative effect. The latter is a physiological impossibility, as the $2 \mathrm{mg} / \mathrm{kg}$ exposure dose was extrapolated from the worst case scenario of the bird consuming 1 $\mathrm{kg}$ of meat at meal. Further to this, at this level of feeding and basal metabolic needs of the birds (Swan et al 2006a, b), the bird is only likely to take in such a high dose every second to third day. Based on the latter scenario and the known complete elimination of drug after 10 half-lives, it extremely unlikely that any meloxicam would still be present within a bird when they feed again two to three days later. 
An interesting finding in this study was the relatively long hepato-renal excretory half-life of 3.78 hours in comparison to the plasma elimination half-life of 0.37 hours. We believe that this may be indicative of the route of elimination, with route of elimination being dependent on the molecular weight (MW) of the drug (Toutain, Ferran \& Bousquet-Mélou 2010). For instance, drug molecules with MW less than 250 are excreted through the renal route while those greater than 300 to 600 are preferably excreted via the biliary route. Variation in the MW range of drug molecules is responsible for interspecies differences with the phenotypic grouping of animals as poor (rabbit, guinea pig, man), good (rats, chickens, dogs) and intermediate biliary excreters (Toutain, Ferran \& Bousquet-Mélou 2010). For meloxicam with a MW of $351.395 \mathrm{~g} / \mathrm{mole}$ coupled with species preferences, the biliary route would likely be the preferred route of elimination of non-metabolised meloxicam in the Cape griffon vulture. In additions, birds unlike mammals do not possess a urinary bladder or urethras. The cloaca represents an embryological precursor of the bladder (coprodeum, urodeum and proctodeum), with the result that urinary clearance is much faster, since there is no urinary retention. The longer hepato-renal half-life would thus be indicative of hepatic clearance of the drug via the bile, as the longer transit time would correspond to gastric transit. Another important mechanism that could also delay excretion is birds, is the retrograde movement of urine into the lower colon where further absorption of water can result, with subsequent further delays in excretory times. (Duke, Degen \& Reynhout 1995).

While the enzyme driving the metabolism remains unknown, we offer the following suggested metabolic pathway based on the metabolites present, half-life of elimination, enzymatic pathways described in from other species, and by contrasting the half-life of diclofenac and meloxicam. Firstly the presence of the two hydroxyl-metabolites identified in this study (Fig. 1) indicate cytochrome metabolism as a phase 1 reaction. From human physiology, meloxicam is known to be metabolised by the CYP2C9 enzymes in metabolically competent people (Bort et al. 1999a, Sanoh et al. 2012, Kumar et al. 2002, Yasar et al. 2001, Chesne et al. 1998), and to a somewhat lower 
extent by CYP3A4 as the alternative pathway (Chesne et al. 1998). Ex vivo studies in humans, have been shown that CYP2C9 has a lower $K_{M}$ value than CYP3A4 for meloxicam, with the latter contributing only slightly to the metabolism even though it is found at a higher content in the liver. Even in people with higher CYP3A4 to CYP2C9 ratios, the maximum reported was still only $40 \%$ metabolism (Chesne et al. 1998) (). Nonetheless the CYP3A4 system is adaptable and can become a primary metabolic pathway as demonstrable in persons with decreased CYP2C9 activity in whom it has been demonstrated that the pharmacokinetics of meloxicam is not compromised (Chesne et al. 1998). In contrast to meloxicam, no effective alternative metabolic pathway appears to be present for diclofenac, with CYP2C9 being the only important enzyme system.

Based on the long half-life of diclofenac we speculate that the vulture has to be deficient in the equivalent CYP2C9 enzyme, which in birds may be one of two enzymes identified as CYP2C18 or CYP2C23a(2H1) which share 60\% homology (Shang, Jiang \& Deng 2013). Obviously while the CYP3A4 will have a compensatory role in metabolism, it alone is unlikely to explain the rapid metabolism of meloxicam, as people with a fully functional CYP3A4 enzyme system still show a prolonged half-life for meloxicam, unless the vulture CYP3A4 enzyme has a lower $K_{M}$ for meloxicam than diclofenac. This latter seems unlikely as this has never been reported in any other species. However, a more likely explanation is that another set of CYP2C enzymes or isoenzymes are involved in the metabolism of meloxicam i.e. metabolism is faster as a result of the total liver cytochrome content having a combined lower $K_{M}$ for meloxicam. This is supported by both the rapid in vivo half-life from this study and from the recent ex vivo liver slice cultures from Cape vulture. For the latter study it was demonstrated that the isolated liver tissue had faster in vitro clearance for meloxicam over diclofenac (Adawaren et al. 2018), which clearly indicates that the liver total enzyme content has the lower $K_{M}$ as the constant is inversely proportional to in vitro clearance. 
The presences of multiple CYP2C enzymes in the metabolism of meloxicam is not an unusual finding and has been previously described in the rat with CYP2C11 and CYP2C7 involved in the metabolism of meloxicam ..Further, support for an additional CYP2C enzymes being involved in metabolism is the second unknown hydroxy metabolite found in the faeces (Fig. 1). To our knowledge the only other time that other hydroxy metabolites of meloxicam have been identified has been in the Koala (Phascolarctos cinereus) where two unknown hydroxy metabolites were identified (Kimble, Li \& Govendir 2013), in conjunction with a rapid half-life of $1.2 \mathrm{~h}$ (Kimble, Li \& Govendir 2013). They also speculated that other CYP enzymes isoforms must be involved in the metabolism of meloxicam, which may be an adaptive mechanism to the diet of the Koalas and a means of conserving energy. The latter would make sense for the vulture, which as the species is adapted to a scavenging life-style that necessitates minimisation of energy requirements (Komen 1992). Unfortunately at this point, we are unsure which enzymes may be, but speculate that it has to be one of the two bird CYP2C9 analogues mentioned above.

\section{Conclusion}

In conclusion, the study shows that the safety of meloxicam in old world vultures is due to the rapid metabolism of meloxicam and not the primary excretion of parent meloxicam as evident in the cat. While speculative we believe this is highly indicative of different pathways in the metabolism of diclofenac and meloxicam in the vulture to that of mammals. It is therefore important to further investigate the orthologous CYP2C and CYP3A enzyme families in order to obtain a further understanding of the metabolism of meloxicam and diclofenac in vultures.

\section{Conflict of interest}

The authors declare that there are no conflicts of interest. 


\section{Acknowledgement}

This research was funded by the National Research Foundation (NRF) of South Africa (Grant no 87772). Furthermore, we kindly extend our profound gratitude to Mrs Kerri Wolter and the entire VulPro technical team for providing the birds as well as technical support in handling procedure throughout the entire period of the research.

We also want to acknowledge the contribution of technical staff in the section of pharmacology and pathology at the Faculty of Veterinary Science for their invaluable support in making the project a success.

\section{References}

Adawaren, E.O., Mukandiwa, L., Njoya, E.M., Bekker, L., Duncan, N. \& Naidoo, V. 2018, "The use of liver slices from the Cape vulture (Gyps coprotheres) to better understand the role of liver toxicity of nonsteroidal anti-inflammatory drugs (NSAIDs) in vultures", Environmental toxicology and pharmacology, vol. 62, pp. 147-155.

Alam, A.B.M.S. 2015a, White-rumped Vulture (Gyps bengalensis) Conservation in Bangladesh:Establishment of Toxic Drug Free Vulture Safe Zones (VSZ) and Monitoring of the Population Trend projrct Quarterly Progress Report (October-December, 2015)., IUCN, Bangladesh.

Alam, A.B.M.S.2. 2015b, White-rumped Vulture (Gyps bengalensis) Conservation in Bangladesh:Establishment of Toxic Drug Free Vulture Safe Zones (VSZ) and Monitoring of the Population Trend projrct Annual Progress Report (March 2014-February, 2015)., IUCN, Bangladesh.

Almeida, D., Maldonado, E., Khan, I., Silva, L., Gilbert, M.T., Zhang, G., Jarvis, E.D., O'Brien, S.J., Johnson, W.E. \& Antunes, A. 2016, "Whole-Genome Identification, Phylogeny, and Evolution of the Cytochrome P450 Family 2 (CYP2) Subfamilies in Birds", Genome biology and evolution, vol. 8, no. 4, pp. 11151131.

Bort, R., Macé, K., Boobis, A., Gómez-Lechón, M., Pfeifer, A. \& Castell, J. 1999a, "Hepatic metabolism of diclofenac: role of human CYP in the minor oxidative pathways", Biochemical pharmacology, vol. 58, no. 5, pp. 787-796.

Bort, R., Ponsoda, X., Jover, R., Gomez-Lechon, M.J. \& Castell, J.V. 1999b, "Diclofenac toxicity to hepatocytes: a role for drug metabolism in cell toxicity", The Journal of pharmacology and experimental therapeutics, vol. 288, no. 1, pp. 65-72. 
Busch, U., Schmid, J., Heinzel, G., Schmaus, H., Baierl, J., Huber, C. \& Roth, W. 1998, "Pharmacokinetics of meloxicam in animals and the relevance to humans", Drug metabolism and disposition: the biological fate of chemicals, vol. 26, no. 6, pp. 576-584.

Chesne, C., Guyomard, C., Guillouzo, A., Schmid, J., Ludwig, E. \& Sauter, T. 1998, "Metabolism of Meloxicam in human liver involves cytochromes P4502C9 and 3A4", Xenobiotica, vol. 28, no. 1, pp. 1-13.

Cuthbert, R.J., Taggart, M.A., Saini, M., Sharma, A., Das, A., Kulkarni, M.D., Deori, P., Ranade, S., Shringarpure, R.N. \& Galligan, T.H. 2016, "Continuing mortality of vultures in India associated with illegal veterinary use of diclofenac and a potential threat from nimesulide", Oryx, vol. 50, no. 1, pp. 104-112.

Cuthbert, R., Taggart, M.A., Prakash, V., Saini, M., Swarup, D., Upreti, S., Mateo, R., Chakraborty, S.S., Deori, P. \& Green, R.E. 2011, "Effectiveness of action in India to reduce exposure of Gyps vultures to the toxic veterinary drug diclofenac", .

Duke, G.E., Degen, A.A. \& Reynhout, J.K. 1995, "Movement of urine in the lower colon and cloaca of ostriches", Condor, , pp. 165-173.

Dutta, N., Mazumdar, K., Seok, S. \& Park, J.H. 2008, "The anti-inflammatory drug Diclofenac retains antilisterial activity in vivo", Letters in applied microbiology, vol. 47, no. 2, pp. 106-111.

Emara, L.H., Emam, M.F., Taha, N.F., Raslan, H.M. \& El-Ashmawy, A.A. 2016, "A Simple and Sensitive HPLC/UV Method for Determination of Meloxicam in Human Plasma for Bioavailability and Bioequivalence Studies.", .

Engelhardt, G. 1996, "Pharmacology of meloxicam, a new non-steroidal anti-inflammatory drug with an improved safety profile through preferential inhibition of COX-2", Rheumatology, vol. 35, no. suppl_1, pp. 4-12.

Faigle, J.W., BÖttcher, I., Godbillon, J., Kriemler, H.P., Schlumpf, E., Schneider, W., Schweizer, A., Stierlin, H. \& Winkler, T. 1988, "A new metabolite of diclofenac sodium in human plasma", Xenobiotica, vol. 18, no. 10, pp. 1191-1197.

Green, R.E., Newton, I., Shultz, S., Cunningham, A.A., Gilbert, M., Pain, D.J. \& Prakash, V. 2004, "Diclofenac poisoning as a cause of vulture population declines across the Indian subcontinent", Journal of Applied Ecology, vol. 41, no. 5, pp. 793-800.

Grudé, P., Guittard, J., Garcia, C., Daoulas, I., Thoulon, F. \& Ebner, T. 2010, "Excretion mass balance evaluation, metabolite profile analysis and metabolite identification in plasma and excreta after oral administration of [14C]-meloxicam to the male cat: preliminary study", Journal of veterinary pharmacology and therapeutics, vol. 33, no. 4, pp. 396-407.

Hasan, S., Ahmed, T., Talib, N. \& Hasan, F. 2005, "Pharmacokinetics of diclofenac sodium in normal man", Pak J Pharm Sci, vol. 18, no. 1, pp. 18-24.

Ishizaki, T., Sasaki, T., Suganuma, T., Horai, Y., Chiba, K., Watanabe, M., Asuke, W. \& Hoshi, H. 1980, "Pharmacokinetics of ketoprofen following single oral, intramuscular and rectal doses and after repeated oral administration", European journal of clinical pharmacology, vol. 18, no. 5, pp. 407-414. 
Khadananda, P., Toby, H.G., Krishna, P.B., Ishana, T., Richard, J.C., Christopher, G.R.B., Racchya, S. \& Narendra, M.B.P. 2016, A decade of vulture conservation in Nepal, USAID, Pakistan.

Kimble, B., Li, K.M. \& Govendir, M. 2013, "Quantitation of meloxicam in the plasma of koalas (Phascolarctos cinereus) by improved high performance liquid chromatography", Journal of veterinary science, vol. 14, no. 1, pp. 7-14.

Kirchheiner, J., Meineke, I., Steinbach, N., Meisel, C., Roots, I. \& Brockmöller, J. 2003, "Pharmacokinetics of diclofenac and inhibition of cyclooxygenases 1 and 2: no relationship to the CYP2C9 genetic polymorphism in humans", British journal of clinical pharmacology, vol. 55, no. 1, pp. 51-61.

Kishida, T., Onozato, T., Kanazawa, T., Tanaka, S. \& Kuroda, J. 2012, "Increase in covalent binding of 5hydroxydiclofenac to hepatic tissues in rats co-treated with lipopolysaccharide and diclofenac: involvement in the onset of diclofenac-induced idiosyncratic hepatotoxicity", The Journal of toxicological sciences, vol. 37, no. 6, pp. 1143-1156.

Komen, J. 1992, "Energy-requirements of adult Cape vultures (Gyps coprotheres)", Journal of Raptor Research, vol. 26, no. 4, pp. 213-218.

Kumar, S., Samuel, K., Subramanian, R., Braun, M.P., Stearns, R.A., Chiu, S.H., Evans, D.C. \& Baillie, T.A. 2002, "Extrapolation of diclofenac clearance from in vitro microsomal metabolism data: role of acyl glucuronidation and sequential oxidative metabolism of the acyl glucuronide", The Journal of pharmacology and experimental therapeutics, vol. 303, no. 3, pp. 969-978.

Lee, C.R., Goldstein, J.A. \& Pieper, J.A. 2002, "Cytochrome P450 2C9 polymorphisms: a comprehensive review of the in-vitro and human data", Pharmacogenetics and Genomics, vol. 12, no. 3, pp. 251-263.

Martignoni, M., Groothuis, G.M. \& de Kanter, R. 2006, "Species differences between mouse, rat, dog, monkey and human CYP-mediated drug metabolism, inhibition and induction", .

Murn, C., Saeed, U., Khan, U. \& Iqbal, S. 2015, "Population and spatial breeding dynamics of a Critically Endangered Oriental White-backed Vulture Gyps bengalensis colony in Sindh Province, Pakistan", Bird Conservation International, vol. 25, no. 4, pp. 415-425.

Naidoo, V., Taggart, M., Duncan, N., Wolter, K., Chipangura, J., Green, R. \& Galligan, T. 2017, "The use of toxicokinetics and exposure studies to show that carprofen in cattle tissue could lead to secondary toxicity and death in wild vultures", Chemosphere, .

Naidoo, V., Wolter, K., Cromarty, A., Bartels, P., Bekker, L., McGaw, L., Taggart, M., Cuthbert, R. \& Swan, G. 2008, "The pharmacokinetics of meloxicam in vultures", Journal of veterinary pharmacology and therapeutics, vol. 31, no. 2, pp. 128-134.

Naidoo, V., Wolter, K., Cuthbert, R. \& Duncan, N. 2009, "Veterinary diclofenac threatens Africa's endangered vulture species", Regulatory toxicology and pharmacology, vol. 53, no. 3, pp. 205-208.

Naidoo, V., Venter, L., Wolter, K., Taggart, M. \& Cuthbert, R. 2010, "The toxicokinetics of ketoprofen in Gyps coprotheres: toxicity due to zero-order metabolism", Archives of Toxicology, vol. 84, no. 10, pp. 761-766.

Naidoo, V., Wolter, K. \& Botha, C.J. 2017, "Lead ingestion as a potential contributing factor to the decline in vulture populations in southern Africa", Environmental research, vol. 152, pp. 150-156. 
Naidoo, V., Wolter, K., Cromarty, A.D., Bartels, P., Bekker, L., Mcgaw, L., Taggart, M.A., Cuthbert, R. \& Swan, G.E. 2008, "The pharmacokinetics of meloxicam in vultures", Journal of veterinary pharmacology and therapeutics, vol. 31, no. 2, pp. 128-134.

Oaks, J.L., Gilbert, M., Virani, M.Z., Watson, R.T., Meteyer, C.U., Rideout, B.A., Shivaprasad, H., Ahmed, S., Chaudhry, M.J.I. \& Arshad, M. 2004, "Diclofenac residues as the cause of vulture population decline in Pakistan", Nature, vol. 427, no. 6975, pp. 630-633.

Oberle, R.L., Das, H., Wong, S.L., Chan, K.K. \& Sawchuk, R.J. 1994, "Pharmacokinetics and metabolism of diclofenac sodium in Yucatan miniature pigs", Pharmaceutical research, vol. 11, no. 5, pp. 698-703.

Polimanti, R., Piacentini, S., Manfellotto, D. \& Fuciarelli, M. 2012, "Human genetic variation of CYP450 superfamily: analysis of functional diversity in worldwide populations", Pharmacogenomics, vol. 13, no. 16, pp. 1951-1960.

Sanoh, S., Horiguchi, A., Sugihara, K., Kotake, Y., Tayama, Y., Uramaru, N., Ohshita, H., Tateno, C., Horie, T., Kitamura, S. \& Ohta, S. 2012, "Predictability of metabolism of ibuprofen and naproxen using chimeric mice with human hepatocytes", Drug metabolism and disposition: the biological fate of chemicals, vol. 40 , no. 12 , pp. $2267-2272$.

Schmid, J., Busch, U., Trummlitz, G., Prox, A., Kaschke, S. \& Wachsmuth, H. 1995, "Meloxicam: metabolic profile and biotransformation products in the rat", Xenobiotica, vol. 25, no. 11, pp. 1219-1236.

Shang, S., Jiang, J. \& Deng, Y. 2013, "Chicken Cytochrome P450 1 A5 Is the Key Enzyme for Metabolizing T-2 Toxin to 3'OH-T-2", International journal of molecular sciences, vol. 14, no. 6, pp. 10809-10818.

Small, R.E. 1989, "Diclofenac sodium", Clinical pharmacy, vol. 8, no. 8, pp. 545-558.

Swan, G., Naidoo, V., Cuthbert, R., Green, R.E., Pain, D.J., Swarup, D., Prakash, V., Taggart, M., Bekker, L. \& Das, D. 2006a, "Removing the threat of diclofenac to critically endangered Asian vultures", PLoS biology, vol. 4, no. 3, pp. e66.

Swan, G.E., Cuthbert, R., Quevedo, M., Green, R.E., Pain, D.J., Bartels, P., Cunningham, A.A., Duncan, N., Meharg, A.A., Oaks, J.L., Parry-Jones, J., Shultz, S., Taggart, M.A., Verdoorn, G. \& Wolter, K. 2006b, "Toxicity of diclofenac to Gyps vultures", Biology letters, vol. 2, no. 2, pp. 279-282.

Torres-Lopez, J.E., Lopez-Munoz, F.J., Castaneda-Hernandez, G., Flores-Murrieta, F.J. \& Granados-Soto, V. 1997, "Pharmacokinetic-pharmacodynamic modeling of the antinociceptive effect of diclofenac in the rat", The Journal of pharmacology and experimental therapeutics, vol. 282, no. 2, pp. 685-690.

Toutain, P., Ferran, A. \& Bousquet-Mélou, A. 2010, "Species differences in pharmacokinetics and pharmacodynamics" in Comparative and veterinary pharmacology Springer, , pp. 19-48.

Tsuchiya, T., Terakawa, M., Ishibashi, K., Noguchi, H. \& Kato, R. 1980, "Disposition and enterohepatic circulation of diclofenac in dogs", Arzneimittel-Forschung, vol. 30, no. 10, pp. 1650-1653.

Yasar, Ü., Eliasson, E., Forslund-Bergengren, C., Tybring, G., Gadd, M., Sjöqvist, F. \& Dahl, M. 2001, "The role of CYP2C9 genotype in the metabolism of diclofenac in vivo and in vitro", European journal of clinical pharmacology, vol. 57, no. 10, pp. 729-735. 
Zanger, U.M. \& Schwab, M. 2013, "Cytochrome P450 enzymes in drug metabolism: regulation of gene expression, enzyme activities, and impact of genetic variation", Pharmacology \& therapeutics, vol. 138 , no. 1 , pp. 103-141. 